\title{
Contributions and Impacts on Health Using New Technologies and Innovative Products
}

\author{
Lílian Lefol Nani Guarieiro ${ }^{1 *}$; Alex Álisson Bandeira Santos ${ }^{2}$ \\ ${ }^{1,2}$ Centro Universitário Senai Cimatec, Integrated Campus of Manufacturing and Technology; Salvador, Bahia, Brazil
}

\begin{abstract}
This edition of the Journal of Bioengineering and Technology Applied to Health brings a selection of four articles presented at the $\mathrm{V}$ International Symposium on Innovation and Technology (SIINTEC).
\end{abstract}

The SIINTEC happens since 2015 at SENAI CIMATEC. The event is annual and promoted by SENAI CIMATEC, Salvador, Bahia, Brazil. The objective of the event is to contribute significantly to the scientific and technological country's development, seeking the massive participation of academy and industry involved in research, development and innovation.

The V SIINTEC was held from October $9^{\text {th }}$ to October $11^{\text {th }}, 2019$, and had focus on: "Circular Economy".

The event gave the opportunity to discuss the main topics related to technological innovations as basis for meeting the challenges of productive processes for the generation and application of business and social.

The contributions and impacts on health using new technologies and innovative products are discussed in the papers selected for publication.

The topics discussed bring discussions about:

- Humanoid prototype development through 3D printing for new technologies;

- Mathematical modeling of the extraction process essential oils;
- The Impact on Human Health of Particulate Matter Arising from Atmospheric Pollution;

- An Innovative Concept of Traceable Device for Monitoring Temperature of Healthcare Products Temperature Sensitive.

The research presented in this edition makes significant contributions to state-of-the-art presentations, innovative medical products, health innovation initiatives, and a review article.

The authors highlighted in their research:

1. The development of a prototype of a humanoid robot by $3 \mathrm{D}$ printing that is as close as possible to the human being;

2.Supercriticaloilextraction fromS.terebinthifolius can result in higher value-added products when integrated to Mathematical models;

3. The fine particles (PM2.5) are the most recurrent incidence of respiratory disease, as they are emitted mainly by industrial activities and vehicular emissions; and

4. The thermo-sensitive health products lack traceability in the health network and that the concept presented contributes to preserving their integrity along the cold chain.

We wish you all an excellent reading.

Received on 27 September 2019; revised 13 October 2019.Address for correspondence: Dr. Lílian Lefol Nani Guarieiro. Centro Universitário SENAI CIMATEC. Av. Orlando Gomes, 1845, Piatã. Zip Code: 41650-010. Salvador, Bahia, Brazil. E-mail: lilian.guarieiro@fieb.org.br

J Bioeng. Biotech. Appl. Health 2019;2(4):111.@ 2019 by SENAI CIMATEC. All rights reserved. 